\title{
Editorial - New Directions
}

We wish to draw the attention of both readers and contributors to a change of emphasis in the Journal's policy. Genetics is an ever expanding branch of science, now developing very rapidly due to the application of new biochemical and molecular techniques to a variety of organisms. In order to help us keep up with these new developments, we have appointed an enlarged and international Editorial Board (listed inside the front cover) with a broad range of interests. We hope that this will encourage an increased flow of significant papers both in the traditional and especially in the newer areas of genetics.

We should also like to emphasize the advantages of Genetical Research for both readers and contributors. These advantages include a wide international circulation coupled with the relatively moderate price of the Journal; the high standard of papers due to careful refereeing and editing, which enables research to be published to its maximal advantage; rapid publication once manuscripts are in acceptable form, priority for publication of significant items as SHORT PAPERS if they are within the limits of six pages of print, the absence of page charges and the gift of 50 free reprints of each paper to its authors. 